\title{
Rapid identification of capybara (Hydrochaeris hydrochaeris) through allele-specific PCR
}

\author{
Flávio Henrique-Silva, Marcelo Cervini and Euclides Matheucci Jr \\ Department of Genetics and Evolution, Federal University of São Carlos, SP, Brasil
}

The capybara is the largest rodent in the world and is widely distributed throughout Central and South America. It is an animal of economic interest due to the pleasant flavor of its meat and higher protein content in comparison to beef and pork meat. The hide, hair and fat also have economic advantages. Thus, as an animal with such high economic potential, it is the target of hunters, even though hunting capybara is prohibited by law in Brazil. Due to their similarities, capybara meat is easily confused with pork meat. This occurs upon the apprehension of the meat from hunters, as well as in some restaurants that serve capybara meat that was slaughtered clandestinely. In both cases, when the meat is confiscated, those responsible for the crimes claim it is pork meat, hindering the enforcement of the law. A practical course was ministered to undergraduate biology students enrolled in the elective course Introduction to Genetic Engineering at Federal University of São Carlos (UFSCar), São Paulo State, Brazil. The objective of the course was to establish and apply a Polymerase Chain Reaction (PCR) assay to identify capybara meat and discriminate it in relation to other types of meat, including pork. Primers were designed based on 12S rRNA, transthyretin and growth hormone receptor genes. The primers generated capybara specific fragments of approximately 220, 290 and 330 bp for transthyretin, $12 \mathrm{~S}$ rRNA and growth hormone receptor, respectively. The duplexes developed in the present work can be used effectively to discriminate capybara meat from other animals, contributing to combating predatory capybara hunting. The results were extensively discussed and the students have contributed to written a paper to be submitted to a publication.

Supported by Fapesp 